\title{
REPRESENTACIÓN PLÁSTICA Y ESCRITA DE ARANJUEZ (ESPAÑA) EN EL MANUSCRITO DE HIERONIMUS GUNDLACH NOVA HISPANIAE REGNORUM DESCRIPTIO (1606): LA IDEALIZACIÓN DE UN REAL SITIO
}

Magdalena Merlos Romero

UNED

Data recepción: 2017/09/08

Data aceptación: 2018/09/27

Contacto autora: mmerlos@aranjuez.es

ORCID: https://orcid.org/0000-0002-1730-2238

\section{RESUMEN}

El presente artículo ejemplifica el proceso de idealización del Real Sitio de Aranjuez durante el Renacimiento con base en el manuscrito Nova Hispaniae Regnorum Descriptio (Biblioteca Nacional de Austria), obra de 1606 del médico alemán Hieronimus Gundlach (1575-1608) en el que relata su viaje por España y Portugal entre 1598 y 1599.

Por una parte se establece el grado de correspondencia entre la imagen plástica del lugar y la descripción que la acompaña en el libro; por otra se analiza el grado de autenticidad de ambas écfrasis respecto de la identidad física del enclave.

El estudio asimismo aborda una comparación de esta imagen de Aranjuez con el tratamiento visual y escrito que el manuscrito ofrece de otras sedes de la Corona española: el Alcázar de Madrid, El Escorial y El Pardo.

Palabras clave: iconografía de la ciudad, Aranjuez (Madrid, España), Hieronimus Gundlach (15751608), literatura de viajes, reales sitios

\section{ABSTRACT}

This article provides examples of the idealisation of the Royal Palace of Aranjuez during the Renaissance, based on the manuscript Nova Hispaniae Regnorum Descriptio (Austrian National Library). Written in 1606 by the German physician Hieronimus Gundlach (1575-1608), it provides an account of his travels through Spain and Portugal in 1598 and 1599.

The article identifies the level of correspondence between the graphic representation of the site and the description of it in Gundlach's book, while also analysing the authenticity of both ekphrases in relation to the physical identity of the place.

This historical-artistic study also compares the image of Aranjuez with the images and written descriptions that the manuscript provides of other royal Spanish sites: the Alcázar of Madrid, El Escorial and El Pardo.

Keywords: iconography of the city, Aranjuez (Madrid, Spain), Hieronimus Gundlach (1575-1608), travel literature, royal sites 


\section{Introducción}

A partir de los últimos años del siglo XVI y durante una centuria conviven dos formas de representar Aranjuez, por una parte vistas imbuidas de valor y función documental, y por otra, vistas sintetizadas e idealizadas. Éstas, por lo general apuntes de viaje o imágenes construidas sobre descripciones literarias, suelen ceñirse al palacio y al jardín, siempre no obstante, contextualizados en el paisaje.

La más antigua de las imágenes sintéticas es un dibujo, acompañado de una descripción escrita, incluido en Nova Hispaniae Regnorum Descriptio, manuscrito de 1606 del médico alemán Hieronimus Gundlach (1575-1608)² en el que relata su viaje por España y Portugal entre 1598 y 15993 (fig. 1).

Se trata de una fuente apenas tratada por la historiografía hispana, con las excepciones de estudios locales referidos a Complutum ${ }^{4}$, Málaga ${ }^{5} \mathrm{y}$ el Alcázar de Madrid ${ }^{6}$ y de la reproducción de la imagen de Aranjuez con una breve referencia al texto descriptivo?

Pese a los escasos datos biográficos que se tienen se sabe que Hieronimus Gundlach nació en Nürnberg. Para Gimeno gozó de una buena posición social y económica y tuvo una buena formación humanística. Salamanqués ${ }^{10}$ va más allá a partir de la lectura de la obra, deduciendo que "no es improbable que...hubiera pertenecido a la corte imperial... tal vez al servicio del emperador", argumentándolo sobre la magnitud de la obra y el empleo de fuentes dignas de una biblioteca muy bien nutrida, el nivel cultural del autor y su interés por la península Ibérica. También lo corrobora el hecho de que el manuscrito formase parte de la misma biblioteca palatina.

En este sentido aunque algunos autores hayan puesto en duda la presencia del médico de Nürnberg en la Península -y así parece atestiguarse en los errores detectados en los escasos estudios del manuscrito, como es el caso del dedicado a Málaga"1-, no es menos cierto que la precisión y algunos detalles en las descripciones y representaciones de los reales sitios parecen confirmar que sí que los conoció personalmente. Aunque el texto, por estar manuscrito en 1606 hace referencia a Felipe III, o a algunos acontecimientos

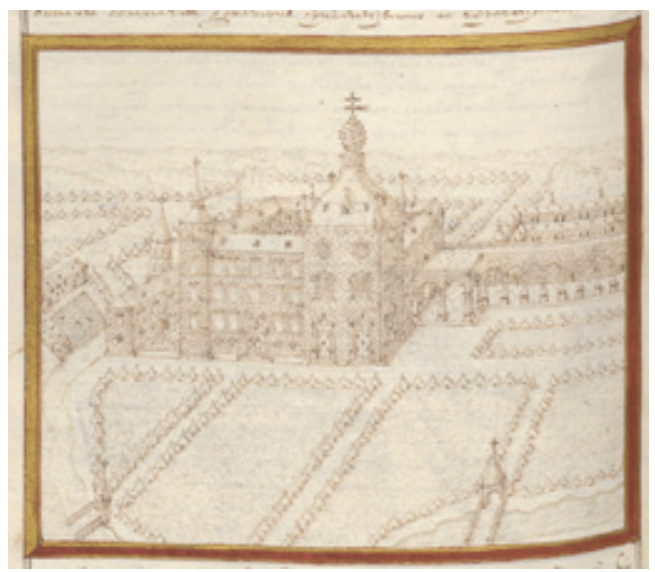

Fig. 1. HIERONIMUS GUNDLACH. Arançoys (Aranjuez). 1606. Viena, (C) Österreichische Nationalbibliothek

posteriores al viaje (como el incendio del palacio de El Pardo ${ }^{2}$ ) todo apunta a que el viaje se realizó entre 1598 y 1599, que Gundlach transitó por España, y que al menos visitó los reales sitios. En cualquier caso, si no es el autor, ha bebido directamente de los testimonios de quienes conocen la realeza española, y estos testimonios han de ser los de los diplomáticos que viajan entre la corte de Praga y la de Madrid.

En este contexto ha de comprenderse la obra de Gundlach. El viaje ha de encuadrarse en los de carácter científico e interés por la Península y particularmente los que se realizan desde el mismo Sacro Imperio, y entenderse como una muestra de las transferencias culturales entre las ramas Habsburgo hispana y germana. Por las fechas, el viajero debió llegar en los días de la enfermedad y muerte de Felipe II, incluso tal vez como miembro de una delegación con motivo de los funerales del Rey Prudente. Las relaciones familiares de los Austrias con los Habsburgo, bastante conocidas y estudiadas, contemplaron desplazamientos e intercambios entre las respectivas cortes imperiales (Madrid, Viena-Praga).

El hecho más determinante fue la estancia de ocho años del futuro emperador Rodolfo II en la corte española (1564-1571), en la que el adolescente inicia su formación científica, despertando su interés por la historia natural y por el Nuevo Mundo que luego desarrollaría en su corte en Praga ${ }^{13}$, en la Kunstkammer del castillo bohemio, la mayor colección de objetos de Europa. Se ha 
destacado la importancia del viaje de Rodolfo y su hermano Ernesto, acompañados de su tutor Adam von Dietrichstein, a Sevilla, donde de primera mano vieron cómo llegaban animales, plantas y objetos procedentes de las Indias con destino a los sitios reales ${ }^{14}$. En Aranjuez el joven Rodolfo conoció la alquimia, por la que sentiría toda su vida especial pasión.

Los lazos entre los imperios germano e hispánico quedan sellados con el matrimonio de Felipe Il con Ana de Austria, boda en la que el hermano de ésta, Rodolfo, ejerce de padrino antes de abandonar España y regresar a Viena.

Más allá de la curiosidad y de la moda, lugares comunes de las cortes europeas, Felipe II incluye el interés por la ciencia en su estrategia imperial mediante la promoción de grandes expediciones científicas al nuevo continente para el conocimiento geográfico, cosmográfico y natural y con la creación de instituciones para la investigación que se focalizaría fundamentalmente en entidades ahora creadas como la biblioteca de El Escorial (iniciada en 1565), el laboratorio de destilación del palacio de Madrid (1572), o la Academia de Matemáticas de Madrid (1582), y en el gran proyecto experimental de Aranjuez. Aquí especialmente en el jardín botánico para la aclimatación de nuevas especies (a sugerencia del médico Andrés Laguna, quien los había conocido en Italia), en el jardín medicinal y en el laboratorio de destilación creado en 1564 (bajo la dirección del flamenco Francisco Holbeque) ${ }^{15}$ para la obtención de esencias con fines terapéuticos, cosméticos, pero también económicos (no descartando Felipe II aun escéptico la alquimia como la solución a sus problemas financieros -el mito de la quintaesencia y la producción de metales preciosos- que finalmente habría de desechar'16). Si bien plantas, animales, huertos, colecciones de pinturas y objetos singulares se distribuían por todos sus reales sitios (que no escapan a las observaciones de Gundlach para Madrid, El Pardo o El Escorial), Aranjuez fue pieza fundamental del programa científico de Felipe II.

\section{El manuscrito}

La escasa bibliografía sobre la obra se hace eco de los principales caracteres externos e internos del manuscrito. Está escrito en latín, la lengua universal del conocimiento en la Edad Moderna, si bien en nuestra opinión no se trata de un conocimiento perfecto del latín clásico, a la vista de ciertos errores de ortografía y de la incorporación de palabras inexactas o directamente sin traducción, tomadas de lenguas vivas como el español o el francés. Esto se puede corroborar simplemente en la transcripción del texto dedicado a Aranjuez, con la presencia de términos como leúcas, strudiocameli o grues (vid. Anexo 1).

La temática del libro es la descripción geográfica e histórica de la Península, con valores que alcanzan aspectos etnográficos, artísticos, culturales, con especial mirada a la Antigüedad (destacan las transcripciones epigráficas, tomadas de fuentes consultadas) y sobre todo científicos, aquí la botánica, lo que no es sorprendente en el caso de un profesional de la medicina.

Con metodología y rigor Gundlach incluye un índice topográfico-onomástico y la relación de las fuentes documentales usadas, entre las que destacan Adolphus Occo, Johanes Gruterus, Andrés Schottus, Jacobo Strada y los botánicos Carolus Clusius y Augerius Busbecquius; autores como Florian Docampo, Francisco Tarrafa, Gómez de Castro; el viajero Andrea Navaggiero y el siciliano asentado en la corte española, Lucio Marineo Sículo; y también españoles como Antonio de Nebrija, Arias Montano, Juan de Mariana, Andres Resende y Ambrosio de Morales. Ello no es óbice para que aparezcan inexactitudes y errores, sobre todo en materia de epigrafía ${ }^{17}$.

Desde el punto de vista cartográfico bebe del trabajo de Abraham Ortelius, Theatrum orbis terrarum (1570) del que también toma información escrita, así como de los clásicos Ptolomeo y Estrabón; y a nivel gráfico la muy difundida Civitatis Orbis Terrarum editada por Georg Braun (Colonia, 1572-1603).

Cada entrada topográfica se cumplimenta con la información que aportan estos autores a modo de compendio. La selección de los enclaves del relato está determinada por los propios hitos de las fuentes que consulta, mientras que la ilustración con dibujos para algunos de ellos parece seguir un criterio guiado por la inclusión o no de los lugares en los álbumes de vistas que conoce y utiliza. 

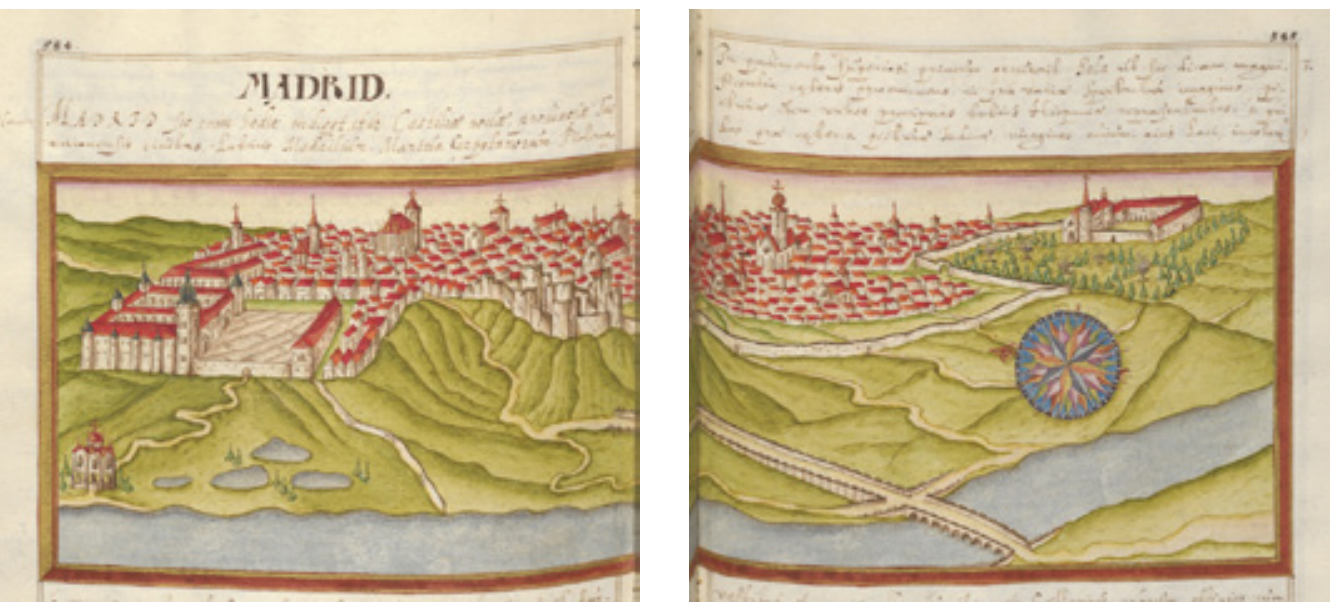

Fig. 2 a y 2 b. HIERONIMUS GUNDLACH. Madrid 1606. Viena, @ Österreichische Nationalbibliothek

Los dibujos que acompañan la narración del periplo por España y Portugal parecen a priori de manos distintas y de difícil adscripción ${ }^{18}$. Sin embargo una visión más detallada permite corroborar una única mano, si bien en unos casos son copia y en otros invención. Esa única mano es la del propio Gundlach, como ya se comprueba en el título y el subtítulo del manuscrito: "Nova Hispaniae Regnorum Descriptio industriam atque; manu Hieremiae Gundlach conscripta \& delineata" 19 .

Como han observado otros autores ${ }^{20}$, las copias toman como modelo los grabados de ciudades de Joris Hoefnagel, obra a la que Gundlach debió acceder sin dificultad: recuérdese además que el artista flamenco llega en 1591 a trabajar en la corte de Rodolfo II. Las imágenes copiadas serían aquellas que ocupan doble página, formato determinado por el carácter de vistas de los originales que reproduce. No ha de descartarse que conociese los originales de Anton Wyngaerde, encargo de Felipe II, que en su mayoría -y entre ellos el de Madrid- tuvieron como destino la biblioteca vienesa.

Tanto los textos sin referente previo alguno como las imágenes parejas que no tienen apoyo en los repertorios gráficos de la época y que por lo tanto habrían de ser propios, ofrecen altos visos de veracidad y precisión, sin ser fieles reflejos de la realidad. Todo parece apuntar a que sobre el bastidor de un viaje a la corte española se completase el panorama peninsular y la nova descrip- tio con el recurso a otras fuentes. De hecho, en los textos dedicados a los reales sitios es donde menos referencias a otros autores se detectan.

El libro se estructura en cinco partes ${ }^{21}$. El primer apartado se dedica a la historia y geografía y el quinto a curiosidades, mientras que las tres secciones centrales siguen un peculiar por caduco criterio geográfico, pues se corresponden con la división territorial romana: Bética, Tarraconense y Lusitania.

El peso de la historia explica el índice general del libro y también el anacronismo al referir enclaves de fundación medieval y moderna, como se constata en la inclusión en la Tarraconense de los reales sitios, lugares no recogidos en las fuentes y repertorios escritos y gráficos tradicionales, y sin una trayectoria en el tiempo que permitiese remontar el relato a la edad antigua.

\section{Los dibujos de los Reales Sitios}

Gundlach, tras describir la antigua capital, Toledo y referenciar brevemente el real sitio de Aceca22, continúa con Madrid (fig. 2 y 3), y los reales sitios de El Pardo (fig.4), Aranjuez (fig. 1) y El Escorial (fig. 5)23.

La autoría de Gundlach, ya anunciada en el subtítulo de la obra, está documentada para el caso del dibujo del alcázar de Madrid: " ... Y así en el Palacio Real (que hemos reproducido al final lo mejor que nuestra mano ha podido con sencillos trazos y sombras)" 24; y el de El Pardo: 


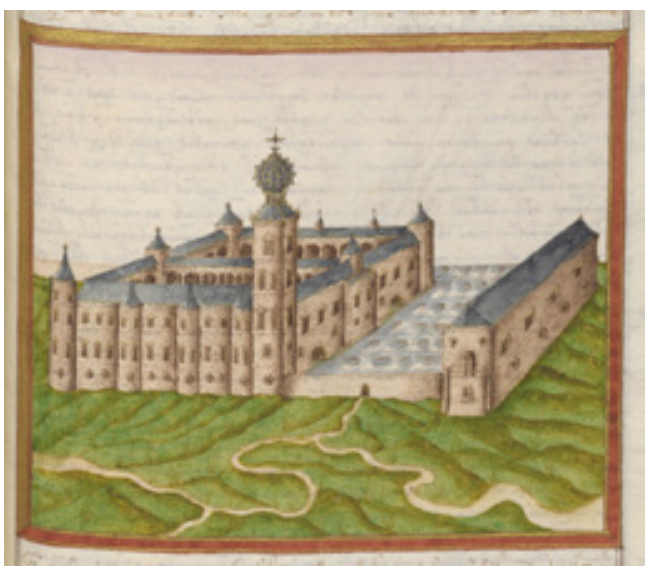

Fig. 3. HIERONIMUS GUNDLACH. Alcázar de Madrid. 1606. Viena, @ Österreichische Nationalbibliothek

"Intueri si placet rudem eius delineationem et xeopgrafiam, quam utcumque apposuimus" 25 , adscripción que se hace extensible a los otros tres reales sitios por la semejanza formal.

El dibujo del alcázar si bien sigue de cerca la representación de la vista de Madrid de Hoefnagel (fig. 6) -y éste la de Anton van Wyngawrde (fig. 7)-, vista que el mismo Gundlach reproduce íntegra en páginas anteriores del manuscrito (aunque para ello eleva la vista desde la altura de los ojos del original a la de pájaro), también parece en la misma medida que sirve de plantilla estilística para los de El Pardo y Aranjuez, aunque las características tanto descriptivas como creativas de éstas últimas hacen pensar en apuntes de viaje y elementos incorporados desde la memoria, luego fusionados tras el regreso a la tierra de origen. Algunos elementos son inventados, como los remates nórdicos de las arquitecturas, que si bien son rasgos de la tipología palatina filipina, no alcanzan a las exuberancias formales de los dibujos de Gundlach.

Ambas estampas no tienen referente iconográfico alguno, y posiblemente sean fruto de la observación directa. En el periodo que transcurre entre el viaje del médico y el manuscrito no existe fuente gráfica editada que haya podido servir de modelo. Sólo se tiene noticia de las vistas de los reales sitios que Jehan L'Hermitte, cortesano flamenco al servicio de Felipe II entre 1587 y 1602, incorpora a su manuscrito Les passetemps (no publicado hasta el siglo XIX), inspiradas por las

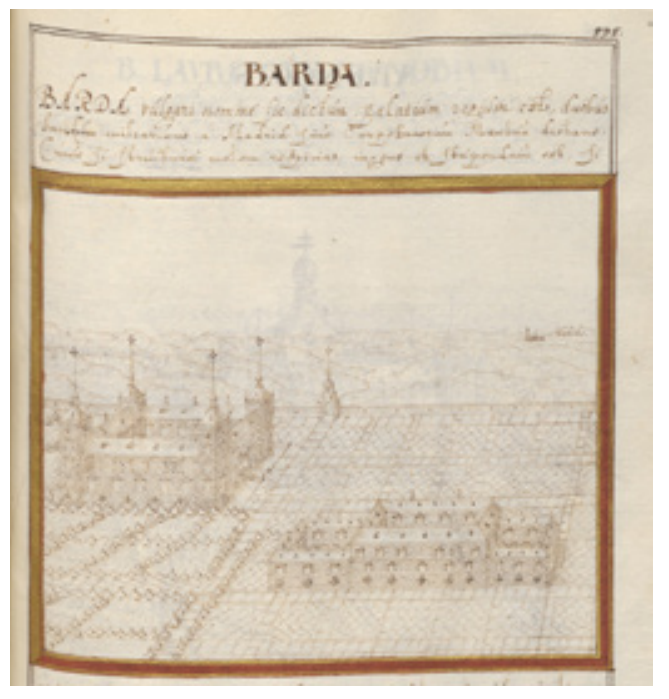

Fig. 4. HIERONIMUS GUNDLACH. Barda (El Pardo). 1606. Viena, (C) Österreichische Nationalbibliothek

que pudo ver en el alcázar madrileño26; pero las diferencias entre los dibujos del flamenco y del germano hacen descartar relación alguna entre ellas; como ejemplo sirva la ausencia en Gundlach de elementos narrativos y de representación animal y humana, tan característicos de L'Hermitte.

No obstante, y reafirmaría la relación de Gundlach con el círculo cultural de la corte praguense, cabe otra posibilidad, y es que el médico germano conociese, bien en España o ya de regreso a su tierra, aquellos óleos que el monarca español ordenase pintar de Aranjuez y Valsaín para Rodolfo II 27, y que junto con varios grabados de El Escorial (posiblemente la serie que Juan de Herrera encarga a Pedro Perret en 1587) le envía en 1589. El germano afirma haber visto en una estancia de la torre dorada del alcázar de Madrid representaciones de El Escorial que bien podrían ser éstas:

in eadem turri aliud est conclauo varias picturas et artificiosissimas imaginum formas, inter quas xeografia Escuarialis mira cum voluptate cernitur, continens habensque alias geometricas e justem monasterij dilineationes, ac descriptiones ${ }^{28}$

Además es sabido que Felipe II encargaba vistas y dibujos de sus propiedades para decorar las paredes de sus palacios con una finalidad tanto ornamental como coreográfica, y que en última 


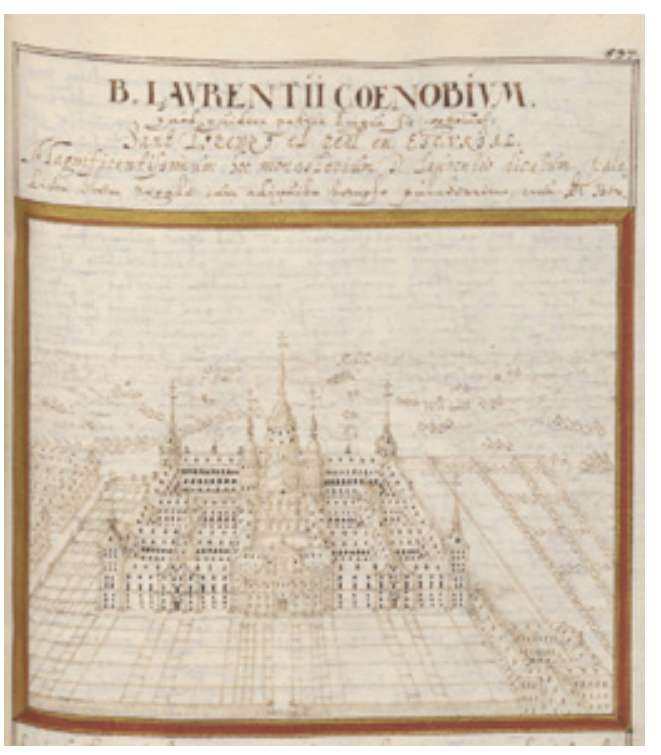

Fig. 5. HIERONIMUS GUNDLACH. B. Lavrentii Çoenobium ( San Lorenzo de El Escorial). 1606. Viena, @ Österreichische Nationalbibliothek

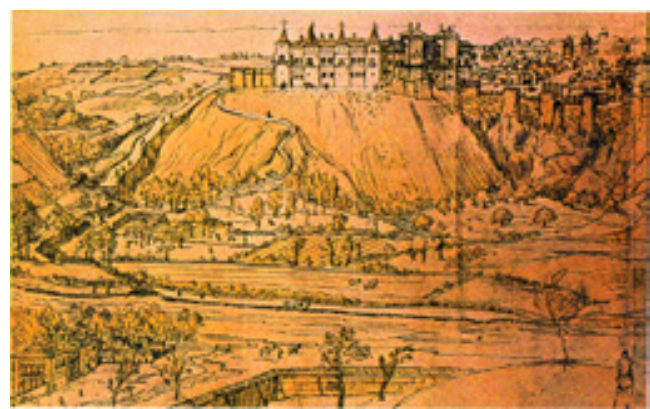

Fig. 6. JORIS HOEFNAGEL. Madrid. 1603 (Braun, Civitatis Orbis Terrarum)

instancia venían a instruir a los visitantes sobre la vasta magnitud de su patrimonio.

Sin embargo este argumento no sería válido para la vista de El Pardo, habida cuenta además de que Valsaín no está entre los reales sitios que Gundlach selecciona.

Todos los dibujos comparten la sencillez de su factura y el formato cuadrangular que ocupa parte de la página en que se insertan, dejando espacio para el texto. No son dibujos de elevada calidad artística, si bien son propios de una persona aficionada y habituada al dibujo, posiblemente como soporte del trabajo científico. En las tres representaciones de El Pardo, Aranjuez y El Escorial (figs. 1, 4, 5) la arquitectura ocupa la mayor parte de la superficie, en una vista de pájaro que deja un espacio proporcionalmente pequeño para contextualizar la casa del rey en el territorio. El efecto aéreo se basa en una perspectiva caballera que apenas contempla los efectos de la escala para marcar la lejanía. Son por otra parte imágenes que se recrean en minuciosos detalles arquitectónicos siguiendo el gusto nórdico, que casi representan sillar por sillar, en contraste con la simplicidad de la composición general. Se observan asimismo idénticas formas en la representación de los árboles y en la disposición casi reticular de los caminos. El primer plano lo ocupan las fachadas de los edificios, paralelas al encuadre.

Y aquí comienzan las diferencias, pues mientras que la representación de El Escorial parte de un eje de simetría central y vertical, las otras dos presentan la crujía lateral a 45 grados, al modo del dibujo del alcázar madrileño y de la vista de Madrid con perspectiva caballera y punto de vista elevado que no aparece en los grabados de la capital de Wyngaerde y Hoefnagel, de los que bebe. Los originales del primero pudo conocerlos en la misma biblioteca palatina de Rodolfo II donde se custodiaban.

La fidelidad alcanzada en el dibujo del monasterio no es tan contundente en las vistas de los otros dos reales sitios aunque la forma de representación sea similar. La fuente del dibujo de El Escorial parece ser uno de los muy difundidos grabados del amberino Pedro Perret ${ }^{29}$ realizado en 1587 e incluido en 1603 en la reedición del Teatrum Orbis Terrarum, grabado del que copia tanto la perspectiva y la composición como el tratamiento de superficies, vegetación y arquitecturas (fig. 8).

\section{Aranjuez dibujado}

El dibujo a tinta sobre papel posee una función ilustrativa ${ }^{30}$. La representación se centra en los hitos arquitectónicos y urbanísticos proyectados por Juan Bautista de Toledo y continuados por sus sucesores, principalmente Juan de Herrera: el palacio, el jardín, las calles arboladas y los puentes ${ }^{31}$.

La composición, un espacio ajardinado centrado por el palacio y con la curva del río bajo él, de 


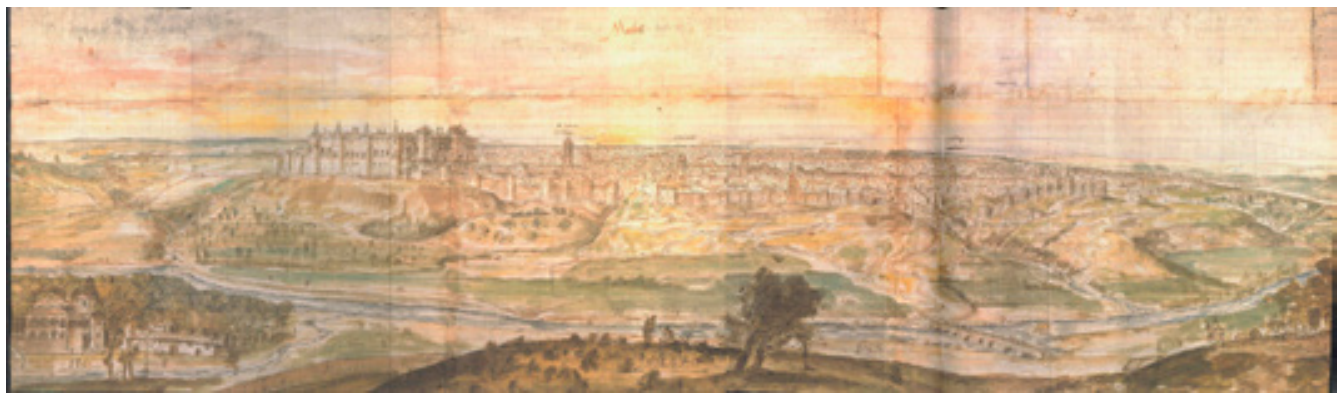

Fig. 7. ANTON VAN WYNGAERDE. Madrid. Viena, @ Österreichische Nationalbibliothek

alguna manera representa esa circunferencia de más de ocho leguas a la que se refiere el texto "hortus omnium delitiarum generibus opulentissimus ac refertissimus cuius circumferentia fore octo leúcas Hispanicas excedit". No existe una correspondencia topográfica absoluta con la realidad si bien el resultado obtiene alta credibilidad. Puede llegar a identificarse la ubicación del palacio respecto de las casas de oficios, enlazados por arcos, las calles arboladas, el espacio de la plaza al sur de palacio, los puentes, los ríos, la representación del territorio ordenado (posiblemente el cruce de calles de Picotajo) y del jardín de la Isla.

Para comprender la lógica topográfica del dibujo va a ser útil la comparación con el fiel, aunque sin pretensiones, referente contemporáneo de Jehan L'Hermite ${ }^{32}$ (fig. 9). Parece que Gundlach no ha comprendido la ordenación geométrica del territorio, que representa, por inercia, de un modo muy similar al de su vista de El Escorial, mediante hileras de árboles monopódicos. Destaca la inexactitud topográfica del alemán en la representación de los dos puentes en primer plano, fruto una confusión de los dos ríos, habitual por otra parte, entre los viajeros, puesto que los meandros del Tajo y la desembocadura del Jarama conforman un laberinto de agua. La representación no distingue ambas corrientes, pues la calle de Entrepuentes, que cruza las huertas de Picotajo, no aparece, de tal modo que los puentes sobre Jarama y Tajo que acotan dicha calle se hacen corresponder con un mismo cauce. Lo cual no impide que se plasme la misma percepción que recibe el visitante que llega por estos puentes desde el camino de Madrid -ubicados en la parte baja del dibujo por donde se inicia la lectura visual- al encontrarse frente a la fachada del edificio, encuadrado entre las líneas rectas de calles arboladas perpendiculares y paralelas. Las torrecillas junto a los puentes pueden emparentarse con los miradores del jardín de la Isla que se representan en las vistas de L'Hermitte y del Museo del Prado ${ }^{33}$, y a las que hace mención entre otros, el viajero flamenco Lamberto Wyts $^{34}$.

Esto no contradice el hecho de que la delimitación del agua y la misma denominación del jardín, ciertamente una isla formada mediante un canal en un meandro del río, desconcierte a los visitantes. Prevalece la imagen de un palacio y de un jardín ubicados en el fondo de un valle, rodeados de agua por todas partes, a los que se llega por numerosos puentes. Esta visión grabada en la memoria es la que se transfiere al papel. Es la misma de las islas caballerescas ${ }^{35}$ en la que el agua rodea por todas partes uno de esos palacios de fantasiosas arquitecturas en sus chapiteles y torres ${ }^{36}$; es la de las isolas e ínsulas fantásticas, donde los puentes son puertas de iniciación; es la de la isla entre ríos de Francesco Colonna y su Sueño de Polífilo, y también la de una Sforzinda que Filarete estructura mediante canales que parten y derivan del río, y cuya misión es comunicar la ciudad con el territorio.

Esta iconografía de "isla con jardín y palacio" en que se convierten el palacio y el Jardín de la Isla con variaciones formales, será recurrente en futuras descripciones. Cítese la de un anónimo viajero (tal vez Antoine de Brunel) en 1612 quien hace del Tajo la arteria que cruza la propiedad real y el cerco de la isla jardín a la que se accede por dos puentes de madera, como los del dibujo: "le tag passe au milieu du parc et des jardins de l'Aranjuez oú il faict une isle que est un jardin tres bon oú passe por des ponts de bois"; y donde el Jardín de la Isla se describe como isla 


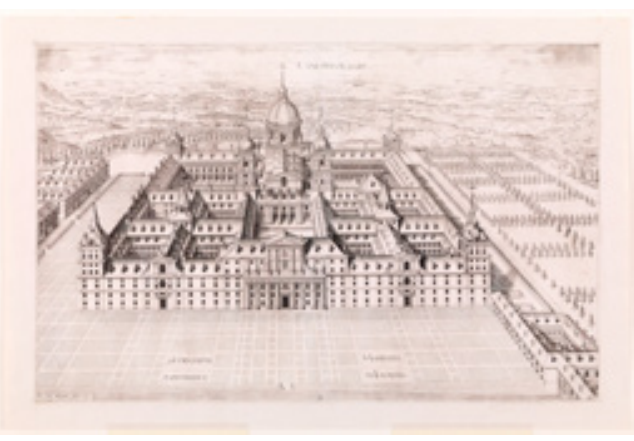

Fig. 8. PETRUS PERRET. Petrus Perret, Scenographia totius fabricae, S. lavrentii in Escoriali (Séptimo Diseño). 1587. Madrid, (C) Biblioteca Nacional de España

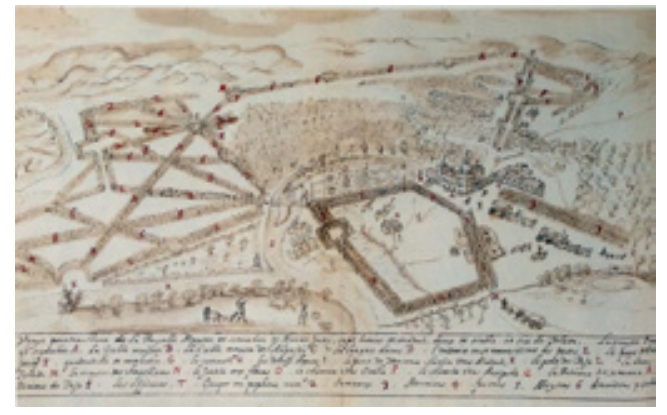

Fig. 9. JEHAN LHERMITTE, Aranjuez. C. 1596. (L'Hermitte, Jehan, El pasatiempos...)

que es un jardín, identidad sugerente desde el punto de vista semántico, de gran carga simbólica (el jardín como isla, otra variante del jardín cerrado, íntimo, de limitado y controlado acceso). Otros ejemplos son el de Baltasar de Monconys, en Aranjuez en 1618:

Le jardin est tout entouré d'eau que le rend une isolé par les deuz rivieres de Tajo \& de Garama, qui se vont iondre au bas des petits ponts de bois tous peints: on y entre du costé de l'eau; tout à l'entour regne une muraille ${ }^{38}$

El de Francois Bertaut en 1659: "Felipe II hizo cortar el célebre río para hacerlo pasar todo alrededor de su jardín o de su parque, que por ese medio es la isla más agradable del mundo" ${ }^{39}$. Y también el testimonio de Bernardin Martin publicado en 1699: "El Tajo y el Jarama, que son dos ríos considerables, atraviesan allí el parque y en varios sitios forman islas muy agradables" 40 .

Por otra parte, no deja de ser una constante en imágenes tal que la de 1699, atribuida a Ro- meyn de Hooghe ${ }^{41}$ (fig. 10) que acompaña este mismo texto de Bernardin Martin, o las que se adentran en el siglo XVIII, como la de los editores Chatelain ${ }^{42}$ y sus reinterpretaciones más o menos delicadas ${ }^{43}$, como la de Hommans, con el palacio y el jardín en un valle rodeados de colinas y agua con el río en primer plano (fig. 11).

En cualquier caso hay una mirada individualizada para aquellos elementos destacados, quedando resuelto el conjunto mediante la combinación de detalles más o menos fidedignos que el texto ha enfatizado con aquellos inventados o inspirados en otras descripciones tópicas. El observador ha sintetizado su recuerdo en un dibujo tan ideal como esencial, un valle entre cerros en el que tienen cabida todos los hitos tangibles del Aranjuez de Felipe II -el territorio sometido al orden de la geometría y ordenado por calles arboladas, los puentes, la casa de oficios, los caracteres arquitectónicos del palacio, incluso los no mencionados en el texto como los ríos. Pese a estar sobredimensionado este palacio entre los meandros y las ondulaciones montañosas y las mismas calles arboladas, alineadas y repetitivas, resulta integrado en la naturaleza. El efecto de transición es evidente, y como sucede con la palabra latina hortus (huerta o jardín) usada en el texto, no hay nada que señale dónde acaba la naturaleza y comienza el artificio.

La composición enmarca adecuadamente el entorno, de tal modo que la naturaleza abierta y el territorio se convierten en el escenario geográfico del núcleo palatino. La lectura se realiza mediante una línea de penetración clásica, de izquierda a derecha, a partir del ángulo inferior y mediante un ascenso en diagonal que marca la profundidad, aunque sin recurrir a la escala de la distancia. Se sigue la vista de pájaro de tradición nórdica para abarcar el conjunto y comprender Aranjuez en su amplia dimensión espacial, a la que hace referencia el texto, pero se emplea una perspectiva caballera y un foco muy cercano que la aleja de las vistas citadas de L'Hermitte y del óleo anónimo del Prado, si bien coinciden en la orientación hacia levante con el palacio como referencia focal; la misma que el visitante tiene del lugar cuando llega a él desde Madrid, a través de las huertas de Picotajo. Aún quedan 150 años para que se forme la ciudad de Aranjuez a espal- 
das del palacio: ahora no existe sino el palacio inserto en la naturaleza y acotado por los ríos.

En este sentido el dibujante logra captar las tres zonas de intervención gradual que caracterizan la ordenación territorial de Aranjuez: palacio; jardín y río; puentes, calles arboladas y huertas como anillo de vegetación de transición hacia la naturaleza sin intervenir.

Como se decía, algunos datos gráficos tal que la inclusión selectiva de detalles arquitectónicos de gran fidelidad, que contrastan con la ausencia de pormenores recogidos en la descripción escrita, inducen a pensar que Gundlach conoció Aranjuez. Queda definido el perímetro del paisaje ordenado, tan exacto en algún detalle como fantasioso en otros, pero sobre todo rico en su expresión sintética, que evidencia qué llamó la atención del autor. La tradición nórdica del dibujo se constata en la eficiencia lineal, la ausencia de difuminados y el nivel de detalle de la representación, idéntico para cualquiera de las zonas del dibujo, desde el primer plano hasta el del fondo. Así se observa la minuciosidad de los sillares, vanos y puertas del palacio, o las arquerías que enlazan al este con las de la casa de oficios. La imagen documenta el volumen del palacio inacabado, con su cortile y la gran torre con cúpula en el ángulo suroeste, la casa de oficios y la gran explanada en el ángulo resultante y nunca ajardinada por su función como escenario de espectáculos; hitos presentes también en las dos las vistas más cercanas en el tiempo, la de L'Hermitte (fig. 9) y la anónima del Museo del Prado.

Es la torre la que domina el conjunto, el volumen de la capilla con su cúpula-chapitel resuelta con plena inventiva a la manera de las nórdicas (algo similar aunque con menos exageración en una obra de un siglo después, la de Bernardin Martin, pero también de origen septentrional ${ }^{44}$ ) (fig.10). Es la misma torre que Lambert Wyts, el acompañante de María de Austria, la futura esposa de Felipe II, y de los archiduques de Austria Alberto y Wenceslao en su viaje a España en $1570^{45}$, describe situada en el paseo más largo de Aranjuez (la calle de la Reina), construida a la manera antigua y con una importante colección de pinturas en su interior ${ }^{46}$. En cualquier caso no ha de obviarse la influencia de la tipología de los palacios y jardines clasicistas de los Países

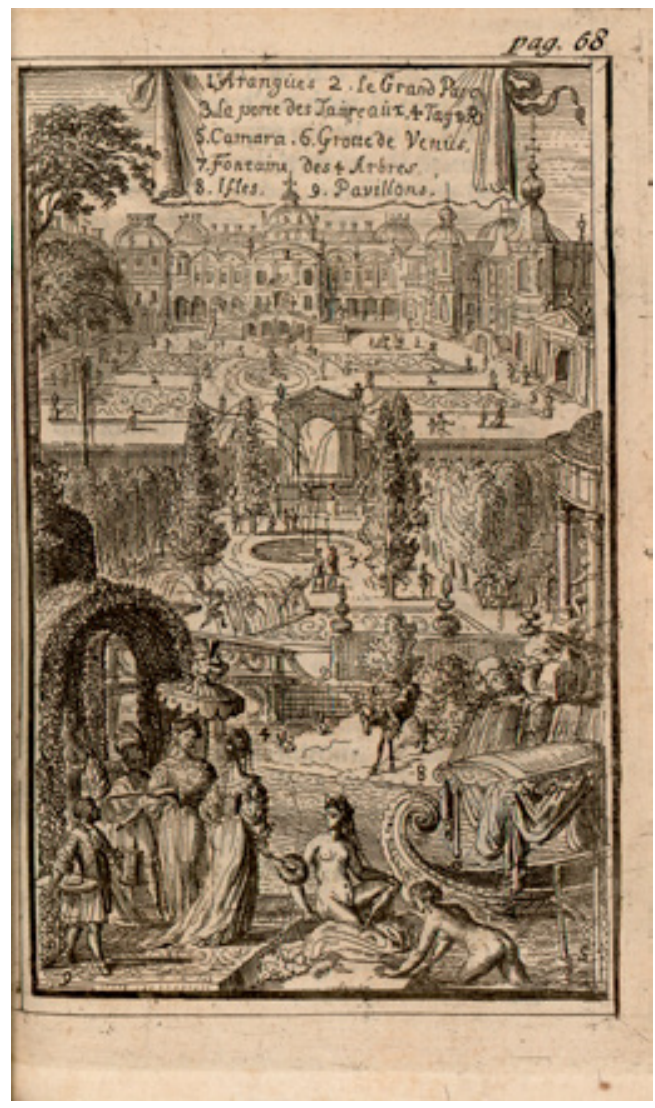

Fig. 10. ROMEYN DE HOOGHE (atrib.) [Aranjuez] (1699 (B. Martin, Voyages...) Madrid, (c) Biblioteca Regional de Madrid

Bajos en los reales sitios españoles, que Felipe príncipe había conocido en su "felicísimo" viaje por Europa entre 1548 y 1551. Aranjuez es una trasposición de las residencias nórdicas, con rasgos como los tejados de ángulo pronunciado y punteados de chimeneas, tan característicos de las arquitecturas filipinas de El Pardo, Valsaín y de la reforma del Alcázar de Segovia.

En otro orden de cosas, no escapa al autor representar el palacio medieval de los maestres de la Orden de Santiago que se mantuvo en pie hasta el reinado de Felipe $\mathrm{V}$.

También destaca el edificio a la izquierda, al otro lado de la ría o canal, que tal vez se corresponda con la oficina de destilación, la Casa de Destilación que los documentos contemporáneos ubican a la entrada del Jardín de la Isla ${ }^{47}$, y que pasa desapercibida en imágenes más o menos 


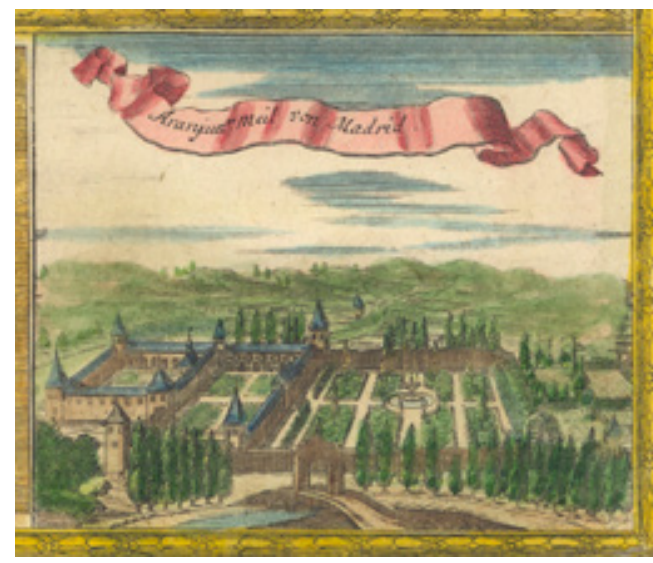

Fig. 11. Aranjuez [1735]. (Accurater... Ed. Iohann Bapt. Homanns). Madrid, (C) Instituto Geográfico Nacional

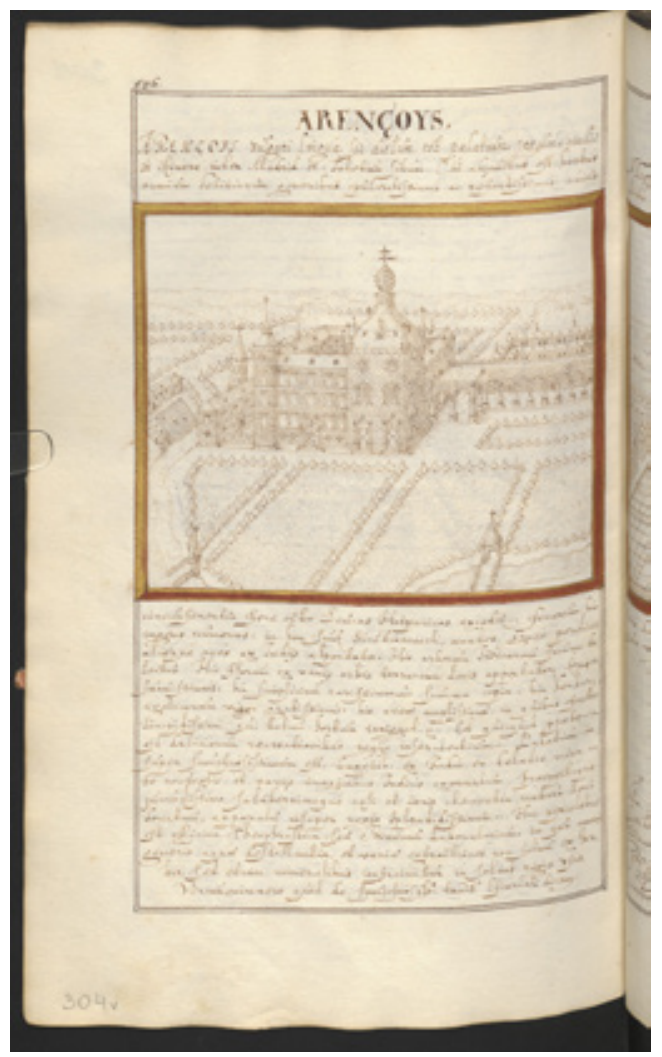

Fig. 12. HIERONIMUS GUNDLACH. Arançoys (Aranjuez). 1606. Página completa. Viena, () Österreichische Nationalbibliothek contemporáneas como el recurrente dibujo de L'Hermitte, o la vista anónima flamenca del Museo del Prado, y cuyo protagonismo en el dibujo ilustraría las líneas de Gundlach dedicadas al laboratorio químico y a la oficina teofrástica (en referencia a la clasificación de las plantas por sus propiedades médicas del Sistema Naturae de Teofrasto) y a su vez ejemplificaría esa mirada selectiva del médico hacia sus propios intereses científicos.

La ilustración de Gundlach, con la serpentina del río, el palacio y el jardín en su jaula de agua y el olvido selectivo de la memoria ha trazado un ideal paisaje tan fantástico como literario, y sin embargo, sustentado en la realidad.

\section{La écfrasis escrita de Aranjuez}

La estructura del texto sigue el patrón utilizado en otras entradas topográficas de la obra (como en los demás reales sitios o en Alcalá de Henares), que comienzan con la referencia al nombre vulgar del lugar, situación geográfica, un apunte sobre el territorio y la dimensión espacial, para pasar a enumerar los hitos físicos característicos del lugar.

El texto de Gundlach (fig. 12 y Anexo 1) se inicia subrayando la crucial situación geográfica de la casa del rey. Así apunta su emplazamiento a mitad de camino entre Madrid y Toledo, aunque no su relación con los ríos: "Arençoys vulgari lingua sic dictum est palatium regium medio in itinere inter Madrid et Toletum situm".

A continuación ensalza las grandes proporciones del enclave y, consciente del significado que las mismas tienen en la percepción de la singularidad del espacio, lo hace coincidir con el hortus "cuius circumferentia fore octo leucas Hispanicas", excepcionalidad que se acentúa al no recurrir Gundlach a comparación alguna con otros mitos geográficos, a diferencia de lo habitual en las literaturas de viaje destinadas a hacer memoria, nombre y fama sin ningún interés específico. El empleo de la palabra hortus, que en latín indistintamente significa huerto y jardín, en número singular contribuye a resaltar tanto las grandes proporciones del territorio intervenido como su coherencia conceptual. Este gran huerto, uno solo y por tanto único jardín paradisiaco, está definido por la abundancia y la variedad. 
El texto eminentemente descriptivo, apoyado en una sintaxis casi telegráfica, se caracteriza por el predominio de sustantivos y adjetivos sobre los verbos, para dar relieve a la magnificencia y singularidad del lugar, que se expresa a través del empleo sistemático de superlativos, propios por otra parte de una protocolaria adulación a la Corona.

Al referir Aranjuez, Gundlach no utiliza las fuentes escritas recurrentes en otros apartados del manuscrito, lo cual induce a pensar en la visión directa del sitio o en el empleo de noticias que han llevado a la corte de Rodolfo II quienes conocen las residencias del rey español. Sirva de ejemplo cómo las descripciones de Ambrosio de Morales que utiliza para otras poblaciones, no quedan reflejadas en la redacción del texto de Aranjuez, ajeno totalmente a las palabras del historiador hispano.

No ha de olvidarse, por otra parte, la cronología del viaje de Gundlach y de su manuscrito, que resulta difícil poner en conexión directa con otros contemporáneos, como Jehan L'Hermitte; Gundlach desde luego no desciende a las anécdotas de L'Hermitte, dejando clara la diferencia entre quien visita un lugar y quien reside en él.

Más plausible es que conociese testimonios literarios de la segunda mitad del siglo XVI, como los poemas de Argensola y García de Tapia o el sintético verso de 1578 de Alonso de Ercilla "Aranjuez, donde natura vertió todas sus flores y verdura" 48 , que pueden explicar cómo la veracidad de las palabras del médico se sostiene en lugares comunes (la abundancia, la feracidad de las tierras, de la flora y de la fauna) que también se observan en el mismo L'Hermitte.

Ahora bien, Gundlach ejemplifica estos tópicos del lugar con detalles que el dibujo no puede precisar y que enumera casi en forma de catálogo. De este modo, se constata un interés especial por los temas naturales y científicos, fundamentalmente fauna y flora.

Las palabras de Gundlach vienen así a potenciar los valores paisajísticos reflejados en el dibujo. De alguna manera allí donde el dibujo no alcanzaba llegó la letra, complementándose la imagen plástica y la escrita. La écfrasis del palacio es un ejemplo elocuente. Mientras que en el gráfico el palacio es el protagonista y ocupa la mayor parte de la superficie, en el texto se limita a un lugar marginal, tanto por la brevedad de los comentarios como por la inserción de los mismos como un punto más a enumerar, entre otros hitos. La tipología del palacio que se muestra gráficamente no aparece en el texto, pero éste se detiene en detalles que plásticamente no se han podido plasmar, algunos sencillamente porque están de puertas adentro. En principio se enfatiza la suntuosidad de un edificio "palatium in super sumptuosissimum est" del que habitualmente los viajeros apuntan la modestia y rusticidad de una casa de campo, a la manera de las villas italianas, una residencia indiscutiblemente excepcional desde el punto de vista artístico, pero construida en piedra y ladrillo e inacabada. Cabe pensar que el epíteto superlativo más bien pueda estar dirigido a las colecciones reales (el coleccionismo como otra de las constantes de los príncipes del Renacimiento), de las que cita los tapices de las Indias entre otras maravillas y rarezas que refiere del nuevo mundo "tapetib.[us] Ex India eo delatis mira arte contextis et varijs imaginibus Indicis ex ornatum prospectuque jucundissimo sabuberrimaque", algunas no importadas, sino producidas en el mismo lugar "ex si et atris elementia natura loci donatum, apparatu insuper regio splendidissimum". Esta atención al interior del palacio en su exuberancia no es frecuente en estas fechas, aunque tiene muestras como la de Wyts ya citada (en referencia a las preciosas pinturas alojadas en la torre ${ }^{49}$ ) y algunas tan memorables como los versos de Lope de Vega en La noche toledana (1605):
Notable es aquel palacio,
galerías, salas, cuadras
mármoles y jaspes lisos,
la capilla y corredores
y aquel retablo divino
del Ticiano, y el reloj,
de tan notable artificio ${ }^{50}$.

La característica conjugación del carácter lúdico del lugar "et quicquid prateria est deliciarum recreationibus regijs insernientium" con su función representativa, productiva y científica, que subraya la personalidad de Felipe II como auténtico príncipe del Renacimiento, será recurrente en la descripción de Gundlach. 
La descripción de Aranjuez pivota en torno al espacio inmenso de paseos arbolados y huertas, a la fauna y a la flora, y a sus recursos estéticos y científicos "cui adjunctus est hortus omnium delitiarum generibus opulentissimus ac refertissimus".

Todo este amplio espacio cultivado se mantiene mediante el riego "hic areae amplissimae in quibus fontes limpidissimi qui totum hortum irrigant". Sobre estas fuentes no se enfatiza su carácter ornamental sino funcional, apuntando en última instancia al sistema hidráulico. Resulta curioso, en este sentido, la ausencia de mención a los ríos, que sin embargo se representan en el dibujo.

En este contexto precisa sobre animales y árboles y otras especies botánicas, algo que no tendrá correspondencia en la imagen gráfica. Así cita a las fieras y destaca las aves (avestruces, cisnes, grullas, perdices) "ferarum hic ingens numerus: in hoc sunt strudiocameli, anates grues perdices aliaque aves ex Indijs a sportatae".

El exotismo de algunos animales, en esa referencia a las Indias, se detecta también en las especies botánicas. Gundlach distingue entre árboles (sin mención a las calles arboladas que sí ha representado visualmente) "hic arborum Indicarum summo delectus", flores traídas del todo el mundo "hic florum ex varijs orbis terrarum locis apportatorj fragor suauissimus" y resalta entre las plantas los simples y las hierbas exóticas -el jardín medicinal ${ }^{51}$ - con valor de coleccionismo en su rareza "hic simplicium rarissimorum summa copia, hic herbar[um] exoticarum vigor gratissimus" pero que también reafirman la cualidad científica de Aranjuez, comparable con jardines contemporáneos como el de los simples de Padua o los botánicos europeos. La creación, estrechamente supervisada por el rey, de jardines botánicos (Casa de Campo, El Escorial y Aranjuez), parece derivar de la sugerencia que recibe del médico Andrés Laguna en 1555, quien ha visto los conformados en Italia, si bien en la península Ibérica existe un sustrato fundamental, el de los jardines botánicos taifas de Sevilla o Toledo.

Está documentada la presencia en Aranjuez de animales exóticos (camellos, avestruces) y la variedad de aves, con espacios para su cría, como la faisanera o los estanques, así como la plantación y cultivo de árboles, plantas ornamentales y medicinales y productos hortícolas ${ }^{52}$, aunque curiosamente la enumeración del texto no se trasluce en el dibujo, como sí se aprecia en otras imágenes contemporáneas, como la minuciosa y a su vez ingenua vista de Jeahnn Lhermitte (fig. 9).

Todos esos datos van conformando implícitamente la imagen de un lugar paradisiaco, construido artificialmente con la traída de animales casi a la manera del arca de Noé, y que más allá de estar recogidos en una ménagerie a la moda coleccionista renacentista ${ }^{53}$, tienen su habitat en el espacio abierto y ajardinado, en el que confluyen plantas de todo el mundo, especialmente de las Indias. Y así sobre un fundamento científico se desarrolla el tema de lo exótico orientado hacia la maravilla y la sorpresa. Tal vez por ello Gundlach no repare en las huertas, el jardín productivo por excelencia que preserva la tradición medieval hispana tanto cristiana como islámica.

La enumeración botánica y zoológica de Gundlach es tan cierta como los testimonios contemporáneos. Puede mencionarse al propio médico de cámara de Felipe II y expedicionario Francisco Hernández al hablar sobre Aranjuez:

muchos de los cuales [árboles exóticos] nos ha hecho familiares la grandeza y cuidado del invictísimo Felipe II, de tal manera que lo que la peregrinación no permitía a nadie en muchos años pueda verse junto en pocos días y lo que la naturaleza repartió en muchas regiones... se vea junto en un rincón de España... Se ocupó en él de un amplio número de árboles, arbustos y plantas con flores, entre ellos, muchos... van viniendo cada día de las Indias y de otras muchas partes ${ }^{54}$.

O la descripción de Aranjuez de Luis de Zapata en 1592

la mas alta, la mas amena, la mas admirable y singular cosa del mundo, traza del paraíso terrenal, donde están juntos cuantas plantas, árboles, yerbas, fuentes, lagos, animales, aves y pescados que en diversas partes en todo el mundo hais5.

De este modo queda subrayado el poder de Felipe II en el planeta, en su intención por reconstruir la creación bíblica en un paraje estratégico a orillas de un río mítico, que ocupa geográficamente el centro de la península Ibérica, y por extensión, del imperio. 
Algunas de las observaciones de Gundlach de carácter sensorial enlazan con la poesía del momento, como la mención a la limpieza de las aguas o al perfume del aire. Pero también se trasluce el interés científico, y por qué no, la intencionalidad ostentosa de quien impera en todo el orbe por conformar este real sitio a imagen de su poder. Junto al mito y los tópicos, en cualquier caso resulta evidente el papel de Felipe Il como príncipe renacentista, al aunar el carácter representativo y lúdico del lugar con el interés personal por la ciencia, y de modo concreto por el conocimiento de la biodiversidad, con la amalgama tan ecléctica como manierista en Aranjuez de las tradiciones autóctonas, flamencas, italianas, y las novedades que el descubrimiento de América aporta.

Asi se entiende que junto a valores sensoriales fruto de la abundancia y la feracidad de la vega, aparezca la mención a la oficina teofrástica y al laboratorio químico, a la destilación del agua y a la extracción de hierbas y minerales, esencias para uso exclusivo del rey:

Hic percelebris est officina theophrastica seu e chimicum laboratorium in qua omnis generis aqua destillantur et variae extractiones non solum ex herbis sed etiam mineralibus conficinutur in solius regis usus.

El jardín científico, a modo de jardín de aclimatación, contaba con flora nórdica y autóctona a la que se incorporaron exóticas especies, cuya selección no respondía sólo a su procedencia y al afán coleccionista, sino a su finalidad. La experimentación científica y su aplicación práctica mediante la destilación atienden a la medicina (con destino a la botica escurialense, y a partir del siglo XVII la Botica Real de Aranjuez), en la misma medida que al lujo cortesano de la perfumería.

La oficina teofrástica y la transformación de minerales resultan ser noticias, sin embargo, más insólitas y por ello sugerentes. Gundlach, como médico, repara en esta oficina inspirada por los principios de Paracelso, el alquimista, botánico y médico, quien inició su carrera precisamente en Austria, y cuyo nombre era Theophrastos, un homenaje al griego autor de los primeros tratados de botánica y del uso medicinal de las plantas. La práctica inexistencia de referencias a la alquimia y al laboratorio como oficina teofrástica en las descripciones de Aranjuez, y esta curiosa atención que le presta el médico podría ser un dato para indagar en la formación de Gundlach, y en la relación de éste con la corte de Rodolfo II. Por otra parte, la información podría conducir a Diego de Santiago, el paracelsiano destilador real que trabajó en los reales sitios, incluido el círculo de Aranjuez ${ }^{56}$. El difuso conocimiento de la presencia física e influencia científica en España de Paracelso ${ }^{57}$, algunas de cuyas obras pasaron a integrar la biblioteca real de El Escorialss, tiene en la existencia de esta oficina teofrásica un punto de reflexión sobre el papel de Aranjuez en la recepción hispana de la obra de Paracelso de la mano de la corona y su posterior introducción en la corte de Praga. Esta asimilación del paracelsismo pudo ser paralela a la constatada afición del futuro emperador austriaco a la alquimia -iniciado por su tío Felipe II durante su estancia en España. A imitación del monarca hispano, para quien la alquimia fue una de sus máximas predilecciones, Rodolfo II concentró en su corte a los grandes alquimistas del momento, creando la Academia Alquimista Praguense.

En cualquier caso todo el texto muestra la coincidencia de los intereses del profesional Gundlach con los del emperador Habsburgo; aunque su misma formación es la que determina tanto el interés por lo científico antes que por lo estético, como su mirada a la naturaleza en detrimento del arte, relegado a un segundo plano.

\section{Las relaciones de Aranjuez con el Sacro Imperio}

Lo que Gundlach ensalza de alguna manera había sido exportado desde España a las cortes de Viena y Praga, con Maximiliano II y Rodolfo II. El mismo Clusius que reseña en su libro de viajes fue posiblemente encargo de Maximiliano II59, editado en 1576, coincidiendo con la sucesión de su hijo Rodolfo.

Maximiliano II acomete las obras de su nuevo palacio de Viena durante los últimos años de la estancia de sus hijos en España, que regresarán a la capital centroeuropea en mayo de 1571. Para esta casa de placer Maximiliano ha tomado los modelos hispanos y especialmente Aranjuez para el diseño de la zona residencial. No sólo hace aco- 
pio de animales, entre ellos camellos y elefantes. En 1565 había recibido los planos de Aranjuez, y en 1568 pide a través de su hermano el archiduque Carlos II, que está en Aranjuez, dibujos de los jardines, y también simientes que desde entonces se harán llegar periódicamente a Viena y Praga ${ }^{60}$.

Ahora bien, el jardín, el gran huerto de Aranjuez no deja de responder a los cánones italianos de simetría, equilibrio y armonía del arte del jardín, inaugurados en Florencia sobre las premisas de Alberti, símbolo de buen gobierno y del control absoluto de la naturaleza por parte del hombre. Las reglas matemáticas con las que Dios crea el mundo y ordena el universo se reflejan en el espacio; y en última instancia contribuyen a fortalecer la idea de paraíso de Aranjuez que Maximilano II importa para su corte de Viena.

Por su parte, Rodolfo II-quien accede al trono en 1576 y traslada la capital de Viena a Praga en 1583, donde fallece en 1612- transforma el castillo bohemio orientado por la estética de los reales sitios de Felipe II. En abril de 1588 había solicitado a Hans Khevenhüller, su embajador en Madrid ${ }^{61}$, dibujos de las que llama casas de placer (/usthäuser) de Felipe II, Aranjuez y El Escorial62, y que deben corresponderse con los dibujos que parecen fueron encargados a Federico Zuccaro, según se deduce de la correspondencia que mantuvo el embajador germano en España con Rodolfo II a lo largo de ese año63. Lo cierto es que los diseños fueron solicitados reiteradamente ${ }^{64}, y$ que incluso aun conocido el definitivo regreso del italiano a Roma, en diciembre de ese año 1588 aún promete al embajador entregarlos pronto "die Zeichnungen von Aranjuezund dem Escurial werde er nächstens übersenden" 65. Debió dejar sin cumplir el encargo, pues a la vista de los documentos parece que Felipe II personalmente se hizo cargo de atender la demanda de Rodolfo II. Así se entiende el informe de Khevenhüller en abril de 1589 en el que indica que Felipe II había ordenado pintar para Rodolfo II óleos de Aranjuez y Valsaín, mientras que de El Escorial enviaba grabados $^{66}$. Parece ser que ésta es la respuesta final al encargo fallido de sendas pinturas a Federico Zuccaro.

El texto de Gundlach coincide plenamente con el mito que se forja en el siglo XV| ${ }^{67}$, y de modo particular con viajeros y diplomáticos vinculados a la corte del Sacro Imperio. Había sido el mismo Carlos, Archiduque de Austria, quien en aquel año de 1569 lo había definido en su misiva a Felipe II, elogiando Aranjuez como "la cosa más rara del mundo"68. En 1583 dedica laudatorias palabras al lugar otro viajero germano, Adam Hochreiter de Wasserburg, del que destaca el jardín alrededor del palacio69. Pero los ejemplos más significativos son los de Lamberto Wyts y Hans Khevenhüller.

El flamenco Lamberto Wyts estuvo en España entre 1570 y 1571, encargado de supervisar el viaje de vuelta a Viena a los archiduques Rodolfo y Ernesto. Wyts deja anotado en su libro el jardín, las especies y los juegos de agua de Aranjuez, la extensión de ricas praderas alrededor de palacio que por esas fechas se está construyendo y la presencia de los hermanos flamencos Holbeque, uno al frente de los jardines, otro de la destilación de plantas ${ }^{70}$.

El embajador imperial Hans Khevenhüller, quien permanecerá en la corte de Felipe II tras el regreso de los jóvenes hasta su fallecimiento en 1606, tiene ocasión de conocer El Escorial, la casa de Valsaín y Aranjuez, "el sitio más apacible y deleitable que su mag[esta]d tiene", a donde le acompaña Juan de Austria⒈ En su diario dejará testimonio de su interés por el lugar, especialmente por la vocación botánica de Aranjuez ${ }^{72}$.

\section{Conclusiones}

La mirada de Gundlach sobre Aranjuez se inscribe en la fama del real sitio forjada en toda Europa durante la segunda mitad del siglo XVI y los años iniciales del XVII. Si bien respecto de la descripción escrita viene a sumarse a los testimonios que durante el reinado de Felipe II se suceden, respecto de la imagen gráfica puede afirmarse que se trata de una de las primeras que de Aranjuez se conservan junto con la de Jehan L'Hermitte, desaparecidas o en paradero desconocido otras que las fuentes y los testimonios contemporáneos refieren. Ambas écfrasis, complementarias y de elevado grado de autenticidad respecto de la identidad física del enclave, poseen la cualidad de equilibrar realidad e ideal, armonizando la fidelidad de la corografía nórdica con los tópicos literarios del sitio como lugar paradisiaco. 
Gundlach se manifiesta preciso en la selección tanto en el texto como en el dibujo de los lugares comunes culturales, artísticos y científicos, si bien construye una insólita imagen visual en la historia iconográfica de Aranjuez.

La écfrasis escrita corrobora la función referencial geopolítica del real sitio. La veracidad de la información y la minuciosa enumeración especialmente de los aspectos naturales, geográficos y científicos del lugar que aporta el médico germano alcanzan un elevado valor documental, con independencia del tono superlativo de sus palabras. Gundlach, además de dejar constancia de sus intereses culturales, viene a confirmar las impresiones de los testimonios contemporáneos, y especialmente los procedentes del Sacro Imperio. Son estas impresiones la riqueza y la feracidad, la exepcionalidad del lugar, y la identificación de su misión tanto lúdica como utilitaria, fruto de la equilibrada y bien resuelta conjunción del arte y la naturaleza.

El dibujo de Aranjuez parece construirse desde su visión directa, tal vez apoyada en alguna representación gráfica; pero siempre con margen al ilustrador para incorporar desde el recuerdo o la imaginación algún elemento ajeno al lugar. Es evidente que el autor no encuentra en la descripción escrita los elementos para construir una imagen que, aunque se ciñe a los cánones del paisaje nórdico, por su singularidad no parece tener precedentes, como tampoco tendrá trascendencia iconográfica.

Por otra parte junto con los otros reales sitios que describe en su obra, Gundlach a través de Aranjuez no sólo deja testimonio de las virtudes de Felipe II como príncipe renacentista, en su interés por la ciencia, la botánica, la fauna, la jardinería, el coleccionismo, una imagen que se aleja del estereotipo saturnino propiciado por la leyenda negra; sino que también a través del real sitio permite que trasluzcan los intereses comunes culturales entre las cortes imperiales hispana y germana. Gundlach viene a constatar la armoniosa fusión de la naturaleza y el artificio que define el paisaje cultural de Aranjuez desde sus orígenes en el siglo XVI.

En última instancia, Gundlach supone una fuente esencial para conocer cómo influyeron la cultura científica de la España del XVI y los intereses personales de Felipe II en la corte y en la figura de Rodolfo Il; así como la forma en que se desarrollaron las relaciones entre ambos imperios. 

ANEXO 1. TRANSCRIPCIÓN Y TRADUC-
CIÓN LITERAL DEL TEXTO SOBRE ARANJUEZ

\section{Transcripción}

ARENÇOYS. Arençoys vulgari lingua sic dictum est palatium regium medio in itinere inter Madrid et Toletum situm. Cui adjunctus est hortus omnium delitiarum generibus opulentissimus ac refertissimus, cuius circumferentia fore octo leúcas Hispanicas excedit. ferarum hic ingens numerus: in hoc sunt strudiocameli, anates, grues perdices aliaque aves ex Indijs a sportatae. Hic arborum Indicarum summo de lectus. Hic florum ex varijs orbis terrarum locis apportatorj fragor suauissimus: hic simplicium rarissimorum summa copia: hic herbar(um) exoticarum vigor gratissimus: hic areae amplissimae in quibus fontes limpidissimi, qui totum hortum irrigant. Et quicquid praeteria est deliciarum recreationibus regijs insernientium. Palatium in super sumptuosissimum est, tapetib. [us] Ex India eo delatis mira ar te contextis et varijs imaginibus Indicis ex ornatum prospectuque jucundissimo saluberrimaque ex si et atris elementia natura loci donatum, apparatu insuper regio splendidissimum. Hic percelebris est officina theophrastica seu chimicum laboratorium in qua omnis generis aquae destillantur, et variae extractiones non solum ex her bis sed etiam mineralibus conficiuntur in solius regis usus.

\section{Traducción literal}

Aranjuez según se dice en lengua vulgar es un palacio regio situado en medio del camino entre Madrid y Toledo, al cual está adjunto un huerto (jardín) opulentísimo y repletísimo en géneros de todas la delicias, cuya circunferencia ha de ser ocho leguas hispánicas. Aquí excede el número ingente de fieras, aquí (hay) avestruces, cisnes, grullas, perdices y otras aves traídas de las Indias, aquí (hay) lo más selecto de árboles indios, aquí al lugar ha de llegar el fragor suavísimo de flores de varios orbes de la tierra, aquí (hay) gran copia de simples rarísimos; aquí (se encuentra) el gratísimo vigor de hierbas exóticas; aquí (hay) áreas amplísimas en las cuales (hay) fuentes limpísimas que riegan todo el huerto, y cualquiera que sea además está rebosante de delicias para recreación del rey. El palacio es suntuosísimo sobremanera, con tapices de la India de arte maravillosa a éste traídos juntos y con varias imágenes indias para el adorno y la agradibilísima contemplación; y sanísimos elementos de sí y de otros, regalo por la naturaleza del lugar, esplendidísimo sobremanera en su aparato regio. Aquí es muy celebrada la oficina teofrásica o laboratorio químico en la cual se destilan aguas de todo género y se recogen varias extracciones no sólo de hierbas sino también de minerales para uso exclusivo del rey. 
NOTAS

H. Gundlach, Nova Hispaniae Regnorum Descriptio, 1606. Osterricheschen Nationalbibliohek, Cod 6481 , p. 4, cfr. V. Salamanqués Pérez, "Alcalá de Henares en un manuscrito de la Biblioteca Nacional de Austria (1598-1599)" en Actas del VII Encuentro de historiadores del Valle de Henares, Guadalajara, 2001, pp. 219-231, p. 219, n. 4.

2 IBN Index-bio-bibliographicus notorum hominum (eds. G. de Olanda B G. O. Gunner), 1973-2000, vol. 97, p. 396 ; cfr V. Salamanqués Pérez, op. cit., p. 221, n. 9.

3 La fecha del viaje en 1598 en $\mathrm{H}$. Gundlach, op. cit., p. 354; cfr. F. Von Unterkircher, «Hieremias Gundlanch: Nova Hispaniae Regnorum Descriptio (Cod. 6481 der Österreichischen Nationalbibliothek)», Jahrbuch der kunsthistorischen Sammlungen in Wien, t. 56, 1960, pp. 165-196.

4 V. Salamanqués Pérez, op. cit.

5 C. González Cravioto, "Málaga y su provincia en el relato manuscrito de Hieremias Gundlach", Péndulo, Revisa de Ingeniería y Humanidades, t. 36, 2015, pp. 101-115, pp. 103-104.

6 J. Herranz, "Dos "nuevos" dibujos del maestro real Gaspar de Vega: El primer plano del Alcázar de Madrid, atribuido a Alonso de Covarrubias, y el plano de la casa de servicios del Palacio de El Pardo", Anuario del Departamento de Historia y Teoría del Arte UAM, t. 9-10, 1997-1998, pp. 117-132, pp.117-119.

7 Dado a conocer en K. Friedrich Rudolf " Antiquitates ad ornatum hortorum spectantes", Coleccionismo, antigüedad clásica y jardín durante el siglo XVI en las cortes de Viena y Praga" en Adán y Eva en Aranjuez, [Cat. Exp. Museo del Prado]. Madrid, 1992, pp. 15-34, p. 31

8 Paulus lenisius, Annaebergae Misniae urbis historia in 2 libros digestae, Dresde, 1605; cfr. H. Gimeno Pascual, Corpus Inscriptionum Latinarum. Anticuarios y epigrafistas. Hieremias Gundlach, s.f. [Consulta: 21/09/2017].

http: www3.uah.es/imagines_cilii/Anticuarios/Textos/hgundlach.htm
9 H. Gimeno Pascual. op. cit.

10 Para el periplo del manuscrito V. Salamanqués Pérez, op. cit. p. 221

11 C. González Cravioto, op. cit., pp. 103-104

12 H. Gundlach, op. cit., p. 595.

${ }^{13}$ W. Eamon, "The Scientific Education of a Renaissance Prince: Archduke Rudolf in the Spanish Court / Vĕdecké vzdělání renesančniho vladařearcivévod: a Rudolf u španělského dvora", in Alchymie a Rudolf II Prague [exhibition catalogue], Artefactum, Prague, 2011, pp. 129-138.

14 E. Meyer-Löwenschwerdt, Der Aufenthalt der Erzherzöge Rudolf und Ernst in Spanien. 1564-1571, Viena, 1927, p. 60. Cfr. W. Eamon, op. cit.

15 M. Rey Bueno, M. E. Alegre Pérez, "Los destiladores de su majestad. Destilación, espagiria y paracelsismo en la corte de Felipe II", Dynamis, t. 21, 2001, pp. 323-350.

${ }^{16}$ F. J. Puerto Sarmiento, "La panacea aurea. Alquimia y destilacion en la corte de Felipe II (1527-1598)", Dynamis, t. 17, 1997, pp. 107-40.

17 V. Salamanqués Pérez, op. cit. y C. Gozálbez Cravioto, op. cit.

${ }^{18} \mathrm{~V}$. Salamanqués Pérez, op. cit.

${ }^{19}$ H. Gundlach, op. cit. p. 4 ; cfr. V. Salamanqués Pérez, op. cit., p. 219 n. 3.

${ }^{20} \mathrm{~V}$. Salamanqués Pérez, op. cit., H. Gimeno Pascual. op. cit., C. Gozálbez Cravioto, op. cit.

21 Sobre la estructura, contenido y caracteres externos del manuscrito $\mathrm{V}$. Salamanqués Pérez, op. cit., pp. 222223.

22 Aquí se reseña Alcántara, que si bien está a orillas del Tajo, se ubica fuera de la Carpetania, muy cercana a la actual frontera con Portugal. Este dato hace pensar desde luego en que no se trata del itinerario de un viaje, sino de un error producto del desconocimiento de los alrededores de Toledo.

${ }^{23}$ H. Gundlach, op. cit. , pp. 584597. Imágenes: Madrid (pp. 584-585), Alcázar de Madrid (p. 589), El Pardo (p. 595), Aranjuez (p. 596), El Escorial ( $p$. 597).

${ }^{24}$ Advertencia de Gundlach al lector detectada por J. Herranz, op. cit., p. 117
25 H. Gundlach, op. cit. p. 595.

26 Valoración de Sáenz de Miera en J. L'Hermitte, El pasatiempos de Jean Lhermite. Memorias de un gentilhombre flamenco en la corte de Felipe II y Felipe III. (ed. J. Sáenz de Miera), Fundación Carolina, Ed. Doce Calles, Madrid, 2005.

27 ÖLA Khevenhüller archiv, 4, 335v.; cfr. K. Friedrich Rudolf, op. cit., p. 31.

H. Voltelini, "Urkunden und Regesten aus dem k. u. k. Haus-, Hofund Staats-Archiv in Wien", Jahrbuch der kunsthistorischen Sammlungen in Wien, t. 13, II, 1892, pp. XXVI-CLXXIV, Reg. 9615. 1589, abril 29. Graz.

"Aranjuez y la casa des bosque de Segovia läst der khünig in öhlfarben stellen, hat aber darumben, das vill weil bedarf, auf dies mall nicht khunen fertig werden; solle, geliebt's gott, volgen".

${ }^{28} \mathrm{H}$. Gundlach, op. cit. p. 585.

29 Petrus Perret, Scenographia totius fabricae, S. lavrentii in Escoriali (Séptimo Diseño). 1587. Biblioteca Nacional de España.

Fue también incluido en el último volumen de 1617 de la obra de Braun Civitates Orbis Terrarum, por lo que numerosos repertorios y fuentes adscriben erróneamente el dibujo a Hoefnagel, quien había visitado la península entre 1563 y 1567, fechas en la obra de El Escorial estaba en sus inicios.

${ }^{30} \mathrm{~F}$. von Unterkircher, op. cit., , pp. 190,235

31 Para Aranjuez en el siglo XVI M. Merlos Romero, Aranjuez y Felipe II, idea y forma de un real sitio, Consejería de Cultura, Comunidad de Madrid, Madrid, 1998.

32 J. L'Hermitte, op. cit.

${ }_{33}$ Anónimo, Vista del Real Sitio de Aranjuez, hacia 1620 (data del Museo h. 1636), Museo del Prado. P07090.

34 Codex Vindobonensis Palatinus (CVP), Osterricheschen Nationalbibliohek, Cod. 3325, fol. 50v.; cfr. K. Friedrich Rudolf, op. cit., p. 27.

35 El tema caballeresco en $V$. Soto Caba, "Paisajes de fábula y fantasía literal: naturaleza y jardines en la narrativa del siglo $\mathrm{XVI}$ ", Jardin y naturaleza en el siglo XVI: Felipe II, el rey íntimo. Actas. Aranjuez: Sociedad Estatal para 
la Conmemoración de los Centenarios de Felipe II y Carlos V, 1998, pp. 387398. En concreto para Aranjuez $M$. Merlos Romero, Aranjuez imagen de un mito romántico, (Tesis doctoral inédita), UNED, 2014.

36 Sobre el símbolo de la isla, la obra clásica de J. E. Cirlot, Diccionario de símbolos, ed. Siruela, Madrid, 2003, y M. Tomé, La isla: utopía, inconsciente y aventura. Hermenéutica simbólica de un tema literario, Universidad de León, León, 1987.

${ }^{37}$ C. Claverie, «Relation d'un voyage en Espagne (1612)», Revue Hispanique, t. LIX, 1923, pp. 359-555, pp. 512-513.

${ }^{38}$ B. de Monconys, Journal des voyages de monsieur de Monconys. Troisieme partie. Voyage d'Espagne, Chez Horace Boissat, Gerorge Remeus, Lyon, 1666, p. 34.

39 J. García Mercadal (ed.), Viajes de extranjeros por España y Portugal, Junta de Castilla y León, Consejería de Educación y Cultura, Valladolid, 1999, 4 vol, vol. III, pp. 409-410.

40 B. Martin, Voyages faits en divers temps en Espagne, en Portugal, en Allemagne, en France, et ailleurs, Par Monsieur $M^{* * * *}$, George Gallet, Amsterdam, 1699.

M. Merlos Romero, "Representación escrita y gráfica de Aranjuez en el libro de viajes de Bernardin Martin (1699)", Anales del Instituto de Estudios Madrileños, t. LVI, 2016, pp. 203236.

${ }^{41}$ M. Merlos Romero, "Representación..."; M. Merlos Romero, De 10 clásico y lo romántico. La imagen de Aranjuez en el siglo de Carlos III, Ayuntamiento de Aranjuez, Aranjuez, 2016, p. 362.

42 « Carte du Gouvernement de la Cour d)Espagne, de ses Ordres Militaires, de son gouvernement Eclesiastique et celuy des autres Etats de cette Monarchie dans L'Europe ", en Atlas historique, ou nouvelle introduction à I'Histoire, à la Chronologie et à la Géographie Ancienne et Moderne, représentée dans de nouvelles cartes, ... par Mr. Ci ${ }^{*} \hat{\imath}^{*} \hat{\imath}$... Avec des dissertations sur I'Histoire de chaque Etat, par Mr. Gueudeville, Frères Châtelain, Amsterdam, 1713-1720.
43 Accurater Grundis der Konigl. Spanischen Haupt und Residentz Stadt Madrit mit denen Prospectendes Könige. Schlo sses und andern lust Gebauen, Ed. Iohann Bapt. Homanns, Nuremberg [1735]. Instituto Geográfico Nacional. Cartografías, 0487-10-H-21.

44 Romeyn de Hooghe (atrib.), Aranjuez, en B. Martin, op. cit.

45 La relación del viaje por España de Lamberto Wyts se conoce por el extracto del Codex Vindobonensis Palatinus (CVP), (Osterricheschen Nationalbibliohek, Cod. 3325) realizado por Gachard y titulado Voyages de Lambert Wyts, malinois, en Espagne, en Turquie et en Allemagne) y publicado en M. Gachard, "Notice des manuscrits concernant I'histoire de la Belgique qui existent à la Bibliothèque impériale, à Vienne ", Bulletin de la Commission royale d'Histoire, t. 5, 1863, pp. 235-390, p. 311.

46 Codex Vindobonensis Palatinus (CVP), Osterricheschen Nationalbibliohek, Cod. 3325, fol. 50v.; cfr. K. Friedrich Rudolf, op. cit., p. 27.

47 Con motivo de las obras de ampliación del palacio en 1636 se resuelve que "se mudase la destilación de aguas que estaba a la entrada del jardín de la Isla, porque la obra nueva de la Casa Real se había de empezar, continuando el cuarto y el trascuarto de la Reina que mira al levante" (J. A. Álvarez de Quindós, Descripción histórica del Real Bosque y Casa de Aranjuez, Madrid, 1804. Ed. fac. Doce Calles, Aranjuez, 1993, p.198; Cfr. M. Merlos Romero, Aranjuez y Felipe II ..., p. 110).

Se decide la construcción de la casa en 1562 (Archivo General de Simancas, Casas y Sitios Reales, Leg 251.2 fol. 73, cfr. M. Merlos Romero, Aranjuez y Felipe II ..., p. 142).

Es descrita en 1583 como "casa en el jardin de la ysla donde distilan aguas y azeites de las flores y otras yervas que ay en las guertas y jardines ..." reiterándose en el mismo documento su ubicación en el jardín "Jardin Grande de la Isla. Ay en el dicho heredamento un jardín grande que llaman de la ysla questa junto a la casa rreal vieja. En la cual ay muchos arboles frutales demas de los quadros de jardines y ansimismo ay en el una casa donde se distilan las aguas y azeites medicinales de las yerbas e plantas que ay en los dichos jardines" (AGP Administraciones Patrimoniales, Ca 14423, 1583, Relación de la hacienda, posesiones, preeminencias, derechos y aprovechamientos del Real Heredamiento de Aranjuez, fol. 38 bis r.y v., fol. 22; cfr. Cfr. M. Merlos Romero, Aranjuez y Felipe II ..., ap. doc. 38, 42).

48 A. de Ercilla, La Araucana, 1578, II parte, Canto XXVII. (Ed. Cátedra, Madrid, 2011).

49 Codex Vindobonensis Palatinus (CVP), Osterricheschen Nationalbibliohek, Cod. 3325, fol. 50v.; cfr. K. Friedrich Rudolf, op. cit., p. 27.

50 L. de Vega, La Noche Toledana. Tercera parte de las Comedias de Lope de Vega y otros auctores con sus loas y entremeses las quales comedias van en la oja precedente, Sebastián de Cormellas, Barcelona, 1612; Miguel Serrano de Vargas, Madrid, 1613. Ed. digital Biblioteca Nacional, Madrid 2009.

51 J. M. López Piñero, El Códice Pomar (ca 1590) el interés de Felipe II por la historia natural y la expedición Hernández a América, Instituto de Estudios documentales sobre la ciencia-CSICUniversidad de Valencia, Valencia 1991. El autor señala, según las palabras del médico Francisco Vallés (1587) el abastecimiento de plantas desde Andalucía, América y otros lugares para en Aranjuez formar "jardines de todo género de plantas exóticas de interés médico".

52 M. Merlos, Aranjuez y Felipe II ...

53 A. Pérez de Tudela, A. J. Gschwend, «Renaissance menageries. Exotic animals and pets at the Habsburg Courts in Iberia and Central Europe», en Early Modern Zoology: The Construction of Animals in Science, Literature and the Visual Arts (2 vols), Brill, 2007, pp. 427-456

${ }^{54}$ Cfr. J. M. López Piñero, op. cit., pp. 16-17. Este aserto sin embargo no será difundido en la época, pues a pesar de ser la primera traducción al castellano de la Historia Natural de Plinio el Viejo, el manuscrito de Francisco Hernández (1567-1570) no llegó a publicarse hasta el siglo XX.

55 L. Zapata, Miscelánea. Silva de casos curiosos, 1592; cfr. J. Fradejas Lebrero, Geografía literaria de la provincia 
de Madrid. Instituto de Estudios Madrileños, CSIC, Madrid, 1992.

${ }^{56}$ F. J. Puerto Sarmiento, op. Cit., pp. 128.

57 J. M. López Piñero, "Química y medicina en la España de los siglos XVI y XVII. La influencia de Paracelso", Cuadernos de Historia de la Medicina Española, 11, 1972, pp. 17-54

${ }^{58}$ F. J. Puerto Sarmiento, op. Cit., pp 127-128; F. J. Puerto Sarmiento "Los destilatorios del Monasterio de El Escorial: alquimia y paracelsismo en la corte de Felipe II", en Felipe II, la ciencia y la técnica, Actas, E. Martínez Ruiz (dir.), Madrid, 1999, pp. 429-446.

59 K. Friedrich Rudolf, op. cit., p. 30.

${ }^{60}$ K. Friedrich Rudolf, op. cit., p. 25-27.

${ }^{61}$ Para el papel de Hans Khevenhüller en el coleccionismo de los Habsburgo vid. P. Jiménez Díaz, El coleccionismo manierista de los Austrias. Entre Felipe 11 y Rodolfo II, Sociedad Estatal para la Conmemoración de los Centenarios de Felipe II y Carlos V, Madrid, 2001.

62 ÖLA Khevenhüller archiv, 4, 335v.; cfr. K. Friedrich Rudolf, op. cit., p. 31.

"Freiherr von Khevenhüller schreibt unter Anderem an Kaiser Rudolf IL, er hoffe, die disegnos des khönigs lustheuser, furnemblich aber des Escural und Aranjoes, in Kurfem fu erhalten, die er dann mit der nächsten Post dem Kaiser fusenden werde".

(H. Voltelini, op. cit., Reg. 9560. 1588 April 2, Madrid.)
63 H. Voltelini, op. cit. Reg. 9583 (1588, noviembre, 11, Madrid) y Reg. 9590 (1588, diciembre, 10. Madrid).

Se ha planteado que la coincidencia en Praga de Zuccaro con el emperador fuese una razón para el encargo de trabajos al pintor, que por otra parte no están identificados (M. M. Moralejo Ortega, "Nuevos datos acerca de los viajes de Federico Zuccari (1539?1609) por las cortes europeas: las aportaciones inéditas de Ottaviano Zuccari primogénito del artista", en El arte y el viaje (coord. Por M. Cabañas Bravo, A. López-yarto Elizalde, W. Rincón García), CSIC, Madrid, 2011, pp. 11-32, p. 25.). Resulta sugerente pensar que podrían ser estas vistas.

64 Khevenhüller informa el 11 de noviembre sobre el trabajo casi terminado de Zuccaro para El Escorial, que no ha gustado a Felipe II, mientras que teme por su propio encargo

"was dann die disegnos Aranjues und san Lorenco el Real betrufft, die sollen nicht fällen und möcht's villeichtobberuerter mein diener auch mitfuehren".

(H. Voltelini, op. cit. Reg. 9583. 1588, noviembre, 11, Madrid.)

65 " Hans Freiherr von Khevenhüller berichtet an Kaiser Rudolf IL über den Maler Federico Zuccaro: Federico Zucaro verruckt morgen mit dem bäbstlichen nuntio Speciano nach Italia. Beruerter Zucaro hat in seinen hieigen werken nicht sondere satisfaction geben, begert zu wissen, was euer kais. maj. für gemähl, ob von historien oder fabln sein, haben wellen, das euer kais. maj. ihn nach Rhom zu wissen machen allergenedigist bevelhen werden. Die
Zeichnungen von Aranjuez und dem Escurial werde er nächstens übersenden".

(H. Voltelini, op. cit. Reg. 9590. 1588, diciembre, 10. Madrid.)

66 ÖLA Khevenhüller archiv, 4, 335v.; cfr. K. Friedrich Rudolf, op. cit., p. 31.

H. Voltelini, op. cit, reg. 9615. 1589, abril 29.

67 Para la imagen de Aranjuez en los escritores y viajeros del siglo XVI, M. Merlos Romero, Aranjuez, imagen...

68 Año 1569. AGP Estado (E) 66032. 32. Cfr. K. Friedrich Rudolf, "Grazer und madrider hof um 1600: malienpolitik, religion und kunst", en Kunst und Geisteswissenschaften aus Graz: Werk und Wirken überregional bedeutsamer Künstler und Gelehrter : vom 15. Jahrhundert bis zur Jahrtausendwende (ed. K. Acham), Böhlau Verlag Wien, 2009, pp. 77-96, p. 80.

69 A. Farinelli, Viajes por España y Portugal desde la edad media hasta el siglo XX; divagaciones bibliográficas, Junta para ampliación de estudios e investigaciones científicas, Centro de Estudios Históricos, Madrid, 1920, p. 136.

70 M. Gachard, op. cit., p. 323.

71 H. Khevenhüller, Diario de Hans Khevenhüller: embajador imperial en la corte de Felipe II. (ed. S. Veronelli, F. Labrador Arroyo), Sociedad Estatal para la Conmemoración de los Centenarios de Felipe II y Carlos V, Madrid, 2001, p. 79.

72 Cfr. K. Friedrich Rudolf, op. cit., p. 30 


\section{REFERENCIAS}

Accurater Grundis der Konigl. Spanischen Haupt und Residentz Stadt Madrit mit denen Prospectendes Könige. Schlo sses und andern lust Gebauen. 1735. Edited by lohann Bapt. Homanns. Nuremberg. España: Instituto Geográfico Nacional. Cartografías, 0487-10-H-21.

Álvarez de Quindós, Juan Antonio. 1804. Descripción histórica del Real Bosque y Casa de Aranjuez. Madrid. 1993. Ed. fac. Aranjuez: Doce Calles.

Anónimo. Vista del Real Sitio de Aranjuez. 1636. Madrid: Museo del Prado. P07090.

Civitates Orbis Terrarum. 1617. Ed. George Braun. Colonia: Braun.

«Carte du Gouvernement de la Cour d'Espagne, de ses Ordres Militaires, de son gouvernement Eclesiastique et celuy des autres Etats de cette Monarchie dans L'Europe. 17131720». In Atlas historique, ou nouvelle introduction à l'Histoire, à la Chronologie et à la Géographie Ancienne et Moderne, représentée dans de nouvelles cartes, ... par Mr. $C^{*} \hat{l}^{\star} \hat{l}^{*}$... Avec des dissertations sur l'Histoire de chaque Etat, par Mr. Gueudeville. Amsterdam: Frères Châtelain.

Cirlot, José Eduardo. 2003. Diccionario de símbolos. Madrid: Siruela.

Claverie, Charles. 1923. "Relation d'un voyage en Espagne (1612)." Revue Hispanique LIX: 359-555.

Codex Vindobonensis Palatinus (CVP). Wien: Osterricheschen Nationalbibliohek. Cod. 3325.

Eamon, William. 2011. "The Scientific Education of a Renaissance Prince: Archduke Rudolf in the Spanish Court / Vědecké vzdělání renesančniho vladařearcivévod: a Rudolf $u$ španělského dvora." In Alchymie a Rudolf II Prague [exhibition catalogue], 129-138. Prague: Artefactum.

Ercilla, Alonso de. La Araucana. 1578. Ed. 2011. Madrid: Cátedra.

Farinelli, Arturo. 1920. Viajes por España y Portugal desde la edad media hasta el siglo XX; divagaciones bibliográficas. Madrid: Junta para ampliación de estudios e investigaciones científicas, Centro de Estudios Históricos.

Gimeno Pascual, Helena. Corpus Inscriptionum Latinarum. Anticuarios y epigrafistas. Hieremias Gundlach, s.f. Accessed Sep 21, 2017. http://www3.uah.es/imagines_cilii/Anticuarios/Textos/hgundlach.htm

Gozalbes Cravioto, Carlos. 2015. "Málaga y su provincia en el relato manuscrito de Hieremias Gundlach." Péndulo. Revista de Ingeniería y Humanidades 36: 101-115.

Gundlach, Hieremias. 1606. Nova Hispaniae Regnorum Descriptio. Wien. Osterricheschen Nationalbibliohek. Cod. 6481.

L'Hermitte, Jean. 2005. El pasatiempos de Jean Lhermite. Memorias de un gentilhombre flamenco en la corte de Felipe II y Felipe III. Edited by Jesús Sáenz de Miera. Madrid: Fundación Carolina - Doce Calles.

Herranz, Juan. 1997-1998. "Dos "nuevos" dibujos del maestro real Gaspar de Vega: El primer plano del Alcázar de Madrid, atribuido a Alonso de Covarrubias, y el plano de la casa de servicios del Palacio de El Pardo." Anuario del Departamento de Historia y Teoría del Arte UAM 9-10: 117-132.

IBN Index-bio-bibliographicus notorum hominum. 1998. Vol. 97. Osnabrück: Biblio Verl.

Jenisch, Paul. 1605. Annaebergae Misniae urbis historia in duos 2 libros digesta. Dresde: Schlütz.

Jiménez Díaz, Pablo. 2001. El coleccionismo manierista de los Austrias. Entre Felipe 11 y Rodolfo II. Madrid: Sociedad Estatal para la Conmemoración de los Centenarios de Felipe II y Carlos V.

Khevenhüller, Hans. 2001. Diario de Hans Khevenhüller: embajador imperial en la corte de Felipe II. Ed. Sara Veronelli, Félix Labrador Arroyo. Madrid: Sociedad Estatal para la Conmemoración de los Centenarios de Felipe II y Carlos V.

López Piñero, José María. 1972. “Química y medicina en la España de los siglos XVI y XVII. La influencia de Paracelso." Cuadernos de Historia de la Medicina Española 11: 17-54. 
López Piñero, José María. 1991. El Códice Pomar (ca 1590) el interés de Felipe II por la historia natural y la expedición Hernández a América. Valencia: Instituto de Estudios documentales sobre la ciencia-CSIC- Universidad de Valencia.

Martin, Bernardin. 1699. Voyages faits en divers temps en Espagne, en Portugal, en Allemagne, en France, et ailleurs, Par Monsieur $M^{* * * *}$. Amsterdam : George Gallet.

Merlos, Magdalena. 1998. Aranjuez y Felipe II, idea y forma de un real sitio. Madrid: Consejería de Cultura, Comunidad de Madrid.

Merlos, Magdalena. 2014. "Aranjuez imagen de un mito romántico." PhD diss. Universidad Nacional de Educación a Distancia. Facultad de Geografía e Historia. Departamento de Historia del Arte.

Merlos, Magdalena. 2016. "Representación escrita y gráfica de Aranjuez en el libro de viajes de Bernardin Martin (1699)." Anales del Instituto de Estudios Madrileños LVI: 203-236.

Merlos, Magdalena. 2016. De lo clásico y lo romántico. La imagen de Aranjuez en el siglo de Carlos III. Aranjuez: Ayuntamiento de Aranjuez.

Meyer-Löwenschwerdt, Erwin. 1927. Der Aufenthalt der Erzherzöge Rudolf und Ernst in Spanien. 1564-1571, Wien: Hölder-PichlerTempsky.

Monconys, Baltasar de. 1666. Journal des voyages de monsieur de Monconys. Troisieme partie. Voyage d'Espagne. Lyon: Chez Horace Boissat, Gerorge Remeus.

Moralejo, Macarena. 2011. "Nuevos datos acerca de los viajes de Federico Zuccari (1539?-1609) por las cortes europeas: las aportaciones inéditas de Ottaviano Zuccari primogénito del artista." In El arte y el viaje. Coord. Miguel Cabañas Bravo, Amelia López-Yarto Elizalde, Wifredo Rincón García, 11-32. Madrid: CSIC.

Pérez de Tudela, Almudena and Gschwend, Annemarie Jordan. 2007. "Renaissance menageries. Exotic animals and pets at the Habsburg Courts in Iberia and Central Europe." In Early Modern Zoology: The Construction of Animals in Science, Literature and the Visual Arts. 427456. Leiden/Boston: Brill.

Perret, Petrus. 1587. Scenographia totius fabricae, S. lavrentii in Escoriali (Séptimo Diseño). Biblioteca Nacional de España.

Puerto Sarmiento, Francisco Javier. 1997. "La panacea aurea. Alquimia y destilación en la corte de Felipe II (1527-1598)." Dynamis 17: 107-40.

Puerto Sarmiento, Francisco Javier. 1999. "Los destilatorios del Monasterio de El Escorial: alquimia y paracelsismo en la corte de Felipe II." In Felipe II, la ciencia y la técnica. Coord. Enrique Martínez Ruiz, 429-446. Madrid: Actas.

Rudolf, K. Friedrich. 1992. " "Antiquitates ad ornatum hortorum spectantes", Coleccionismo, antigüedad clásica y jardín durante el siglo XVI en las cortes de Viena y Praga." In Adán y Eva en Aranjuez, [Cat. Exp], 15-34. Madrid: Museo del Prado.

Rudolf, K. Friedrich. 2009. "Grazer und madrider hof um 1600: malienpolitik, religion und kunst." In Kunst und Geisteswissenschaften aus Graz: Werk und Wirken überregional bedeutsamer Künstler und Gelehrter: vom 15. Jahrhundert bis zur Jahrtausendwende. Ed. K. Acham, 77-96. Wien: Böhlau Verlag.

Rey Bueno, Mar and Alegre Pérez, María Esther. 2001. "Los destiladores de su majestad. Destilación, espagiria y paracelsismo en la corte de Felipe II." Dynamis 21: 323-350.

Salamanqués Pérez, Virginia. 2001. "Alcalá de Henares en un manuscrito de la Biblioteca Nacional de Austria (1598-1599)." In Actas del VII Encuentro de historiadores del Valle de Henares, 219-231. Guadalajara: AACHE Ediciones.

Soto Caba, Victoria. 1998. "Paisajes de fábula y fantasía literal: naturaleza y jardines en la narrativa del siglo XVI." In Jardín y naturaleza en el siglo XVI: Felipe II, el rey íntimo. Actas, 387-398. Aranjuez: Sociedad Estatal para la Conmemoración de los Centenarios de Felipe II y Carlos V.

Tomé, Mario. 1987. La isla: utopía, inconsciente y aventura. Hermenéutica simbólica de un tema literario. León: Universidad de León. 
Representación plástica y escrita de Aranjuez (España) en el manuscrito de Hieronimus Gundlach

Unterkircher, F. Von. 1960. "Hieremias Gundlanch: Nova Hispaniae Regnorum Descriptio (Cod. 6481 der Österreichischen Nationalbibliothek)", Jahrbuch der kunsthistorischen Sammlungen in Wien, 56: 165-196.

Vega, Lope de. 1612. La Noche Toledana. Tercera parte de las Comedias de Lope de Vega y otros auctores con sus loas y entremeses las quales comedias van en la oja precedente. Edited by Sebastián de Cormellas, 1612 [edición digital 2009]. Madrid: Biblioteca Nacional.

Vega, Lope de. 1613. La Noche Toledana. Tercera parte de las Comedias de Lope de Vega y otros auctores con sus loas y entremeses las quales comedias van en la oja precedente. Edited by Miguel Serrano de Vargas, 1613 [edición digital 2009]. Madrid: Biblioteca Nacional.
Viajes de extranjeros por España y Portugal. 1999. Ed. José García Mercadal. 4 vols. Valladolid: Junta de Castilla y León, Consejería de Educación y Cultura.

Voltelini, Hans. 1892. "Urkunden und Regesten aus dem k. u. k. Haus-, Hof- und Staats-Archiv in Wien." Jahrbuch der kunsthistorischen Sammlungen in Wien 13, II: XXVI-CLXXIV.

Wyts, Lambert. 1863. “Voyages de Lambert Wyts, malinois, en Espagne, en Turquie et en Allemagne." In Notice des manuscrits concernant l'histoire de la Belgique qui existent à la Bibliothèque impériale, à Vienne, edited by M. Gachard. Bulletin de la Commission royale d'Histoire 5: 235-390.

Zapata, Luis. 1592. Miscelánea. Silva de casos curiosos. [191-?]. Madrid: Compañía IberoAméricana de Publicaciones. 